\title{
The Design of Water Quality Monitoring Cloud Platform Based on
}

\section{BS Architecture}

\author{
Chen Yu-jie ${ }^{1, a}$, Liu Pei-xue ${ }^{1, b}$, Jiang Bao-hua ${ }^{1, c}$, Feng Fei ${ }^{1, d}$ \\ Qingdao Huanghai College, Qingdao266427, China \\ achenyujie_cc@163.com, bytulpx@163.com, \\ c1073578901@qq.com, ${ }^{d} 1547752800 @ q q . c o m$
}

Keywords: Browser/Serve, MySQL, Internet+

\begin{abstract}
In recent years, with China's aquaculture industry develops rapidly, aquaculture water quality management information collection, transmission, storage as well as regulation, has got newer and higher requirements. The computer network technology and remote control technology continues to mature, which makes these techniques more and more applicable to aquaculture. At present informatization is the trend for the development of mariculture, this paper designs and implements a $\mathrm{B} / \mathrm{S}$ based aquaculture water quality monitoring cloud platform in mariculture industry. Compared with the traditional $\mathrm{C} / \mathrm{S}$ architecture, the $\mathrm{B} / \mathrm{S}$ architecture model could realize the real-time monitoring of mariculture comprehensive management and on water quality parameters .
\end{abstract}

\section{Introduction}

In aquaculture, water environment is the foundation of Healthy Mariculture, monitoring of water quality parameters is an important technology in aquaculture water quality monitoring system. The traditional $\mathrm{C} / \mathrm{S}$ software architecture, namely Client/Server (client / server) structure. This structure leads to the client and bloated, scattered, difficult to centralized management and maintenance high cost and long cycle. In recent years, the rapid popularization of the Internet and the increasingly fierce competition in the development and application of new technology and new business to a very important position. The new model Internet plus traditional industry more and more people get more attention and support.

This paper according to the characteristics of aquaculture, the integrated use of remote control technology, computer network communication technology and web service technology, based on Interlay idea development platform, in accordance with the thought of software engineering, the design was based on BS architecture of seawater aquaculture water quality monitoring cloud platform to realize the real-time monitoring of mariculture comprehensive management and on water quality parameters.

\section{System overall design}

Site monitoring equipment by wireless module and the controller is connected to the design, real-time acquisition of information by sending to the web server, released through the network of seawater aquaculture water quality parameters, the management personnel can 
through the network for remote statistical analysis, monitoring seawater farms situation in detail, greatly improving the degree of modernization of farming industry.

The overall structure is shown in Figure 1.

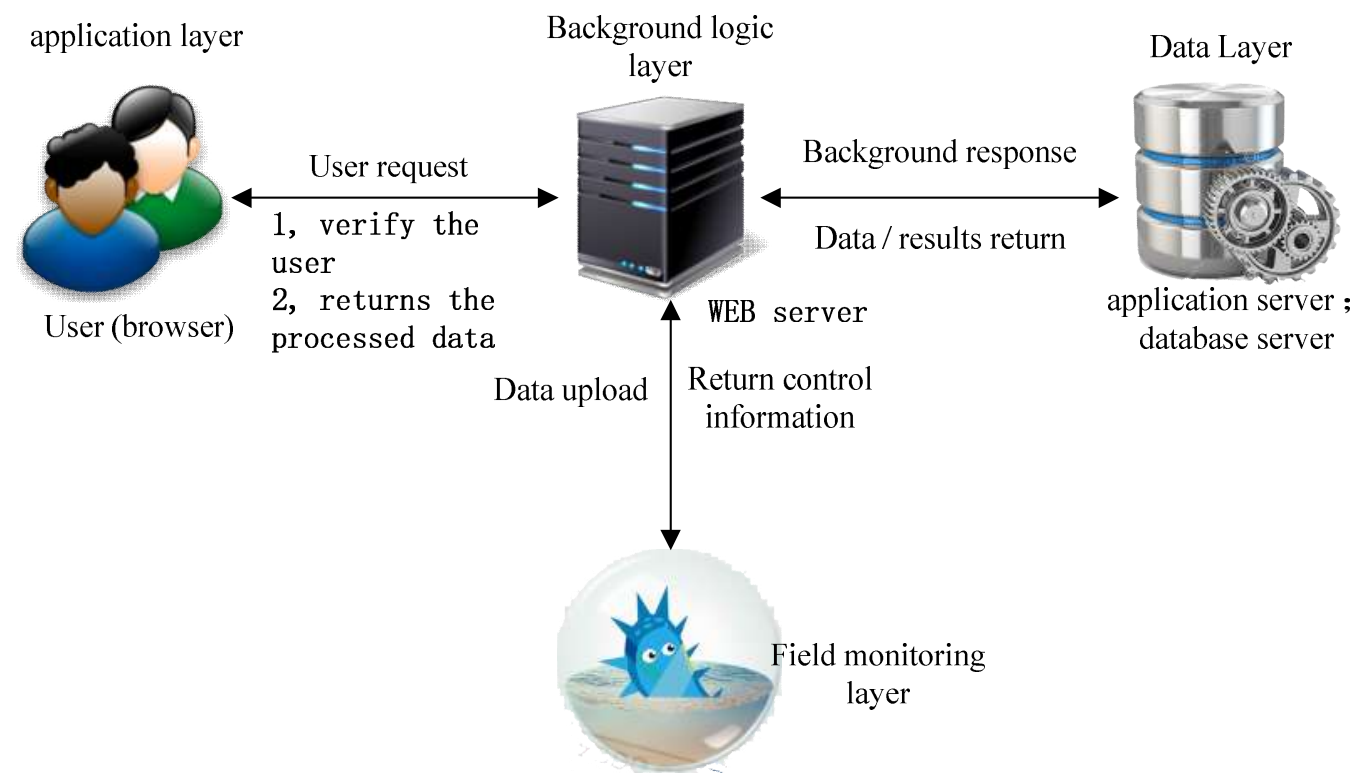

Fig.1 general structure

\section{System development platform}

System customers view layer, control layer and the remote central server web service system is Intellij idea development platform developed based on the structure of.B/S namely (browser) browser and server) server structure [15], the realization of the "fat" server, "thin client thought. Any after the authentication of the user need only through the Internet browser equipment can real-time obtain breeding field of water quality parameters, thus greatly reducing the load of the client, reducing system maintenance and upgrading costs and workload, reduced the overall user cost. And users can also through a variety of Internet devices (mobile phones, pad, etc.) to achieve access.

In this architecture, the application layer, the background logic layer and the data layer are divided into three separate units.

Figure 2 for the $\mathrm{B} / \mathrm{S}$ model architecture.

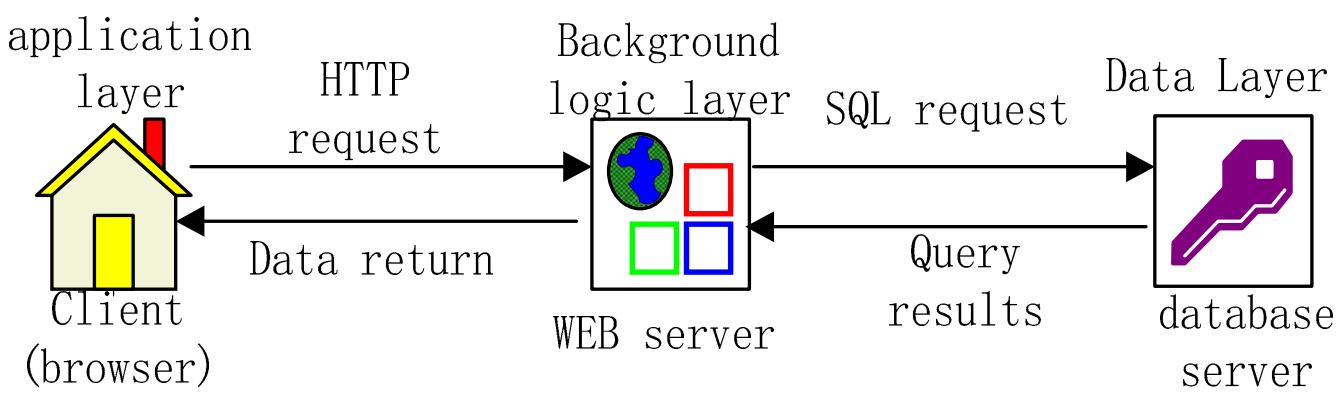

Fig.2 B/S model system structure 


\section{System implementation}

\section{Data transmission}

Seawater farms nodes collect the information, after a series of the lower position machine treatment, according to the provisions of the format of the data through the network to upload to server. Server after processing, and then uploaded to the database server to save.

Node data is the next bit machine sent to the background server through the network, the data format is as follows:

www.skymes.cn/record/insert?msg=\{ “ oxygen ”:5.2, “ $\mathrm{ph}$ ”:8.1, “ sensorID ” : “2016120002”, “temperature” :22.1, "salinity” : 3.18$\}$

The composition of the message is shown in Table 1.

Table 1 node packet format

\begin{tabular}{ccc}
\hline field name & Whether must & Meaning \\
\hline www.skymes.cn & yes & server address \\
/record/insert & yes & Path name \\
msg & yes & parameter name \\
oxygen & no & Oxygen Dissolved \\
ph & no & PH value \\
sensorID & no & panel pointID \\
temperature & no & Temperature value \\
salinity & no & brinishness \\
\hline
\end{tabular}

A node data packet consists of eight parts composition, including the server address, path names, parameter names, dissolved oxygen concentration, $\mathrm{pH}$ value, node ID, the temperature value is. The salinity.

\section{Database design}

Database E-R diagram

Database E-R diagram directly on the user and sensor, recording and sensor, sensor and $\mathrm{pH}$, temperature, salinity and dissolved oxygen concentration of ownership. User, sensor and recording three parts constitute the main part of database, the database E-R diagram as shown in Figure 3.

Database dictionary

Management of mariculture water quality information storage system is is bound to store a large amount of real-time data, appropriate querying and analysis of historical data processing function. Therefore, according to the functional requirements of the system established the following database table:

1. User information table

This table contains two fields, in which the user name is the primary key of the user table, as shown in Fig. 3 and Table 2. 


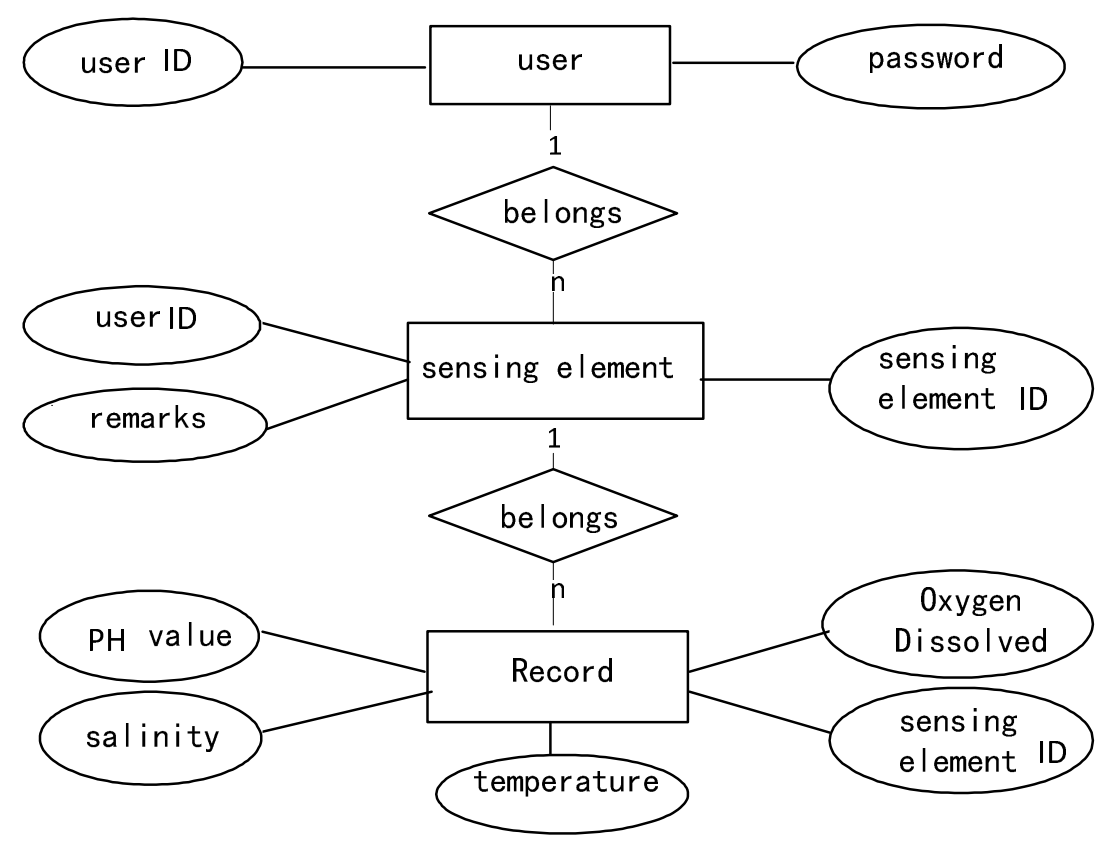

Fig. 3 database E-R diagram

Table 2 user information table

\begin{tabular}{ccccc}
\hline field name & Field type & Field type & primary & remarks \\
\hline username & varchar & 255 & yes & User name \\
password & varchar & 255 & no & password \\
\hline
\end{tabular}

2. Water quality information record

This table contains six fields, which set the data number ID for the primary key, and set to grow automatically. The properties of the entire table are set as shown in Table 3.

Table 3 parameters of water quality information

\begin{tabular}{ccccc}
\hline field name & Field type & Field size & primary & remarks \\
\hline ID & int & 255 & yes & ID node number \\
timestamp & timestamp & 0 & no & $\begin{array}{c}\text { Identify current } \\
\text { collection time } \\
\text { temperature }\end{array}$ \\
ph & float & 0 & no & temperature record \\
oxygen & float & 0 & no & PH value record \\
salinity & float & 0 & no & Do record \\
\hline
\end{tabular}

\section{Implementation of cloud platform}

Cloud platform is the core part of the whole system, it makes the water quality information in any place, to monitor any farm.

\section{Landing module}

System defines two kinds of user permissions, mainly divided into: system administrators, system operator [J]. User login system will automatically identify the user identity information, and the corresponding open access. The system operator can browse all nodes at all seawater aquiculture field data and configuration information; system administrators have the highest authority, in addition to the authority of the system operator can also management 
system operators, and modify configuration information. The login module as shown in Figure 4.

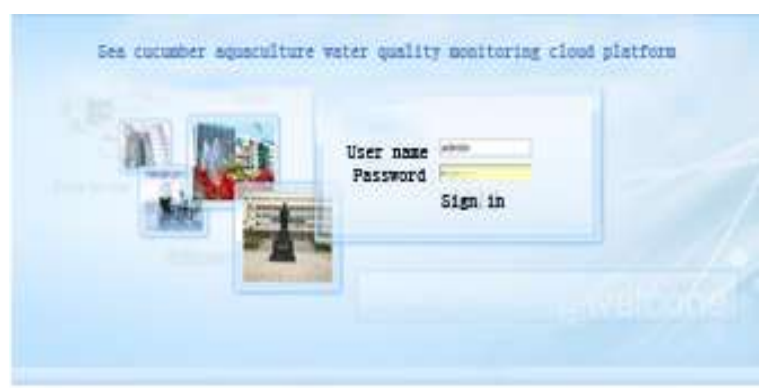

Fig.4 system login interface

Real time data module

Page real-time data to chart in the form of intuitive to system administrators show seawater farms of water quality parameters (including temperature, $\mathrm{pH}$, dissolved oxygen, salinity), and can choose different mariculture understand information related to water quality parameters. In the right hand side of the page will also list the site the warning message.

Real time data display module is shown in Figure 5.

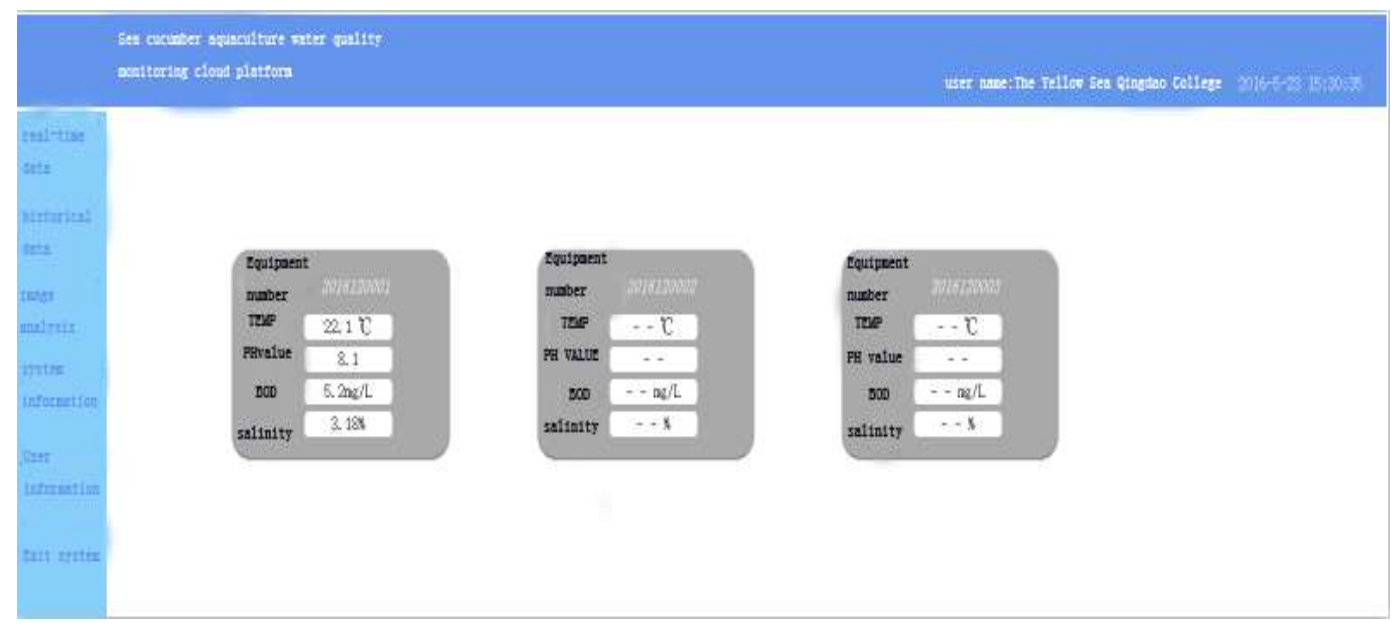

Fig.5 real time data module

Data query module

Data query module is the main function of the previous historical data management and display. The system will collect the data stored in the database, the administrator can browse the data, analysis and export printing.

The data query module is shown in Figure 6.

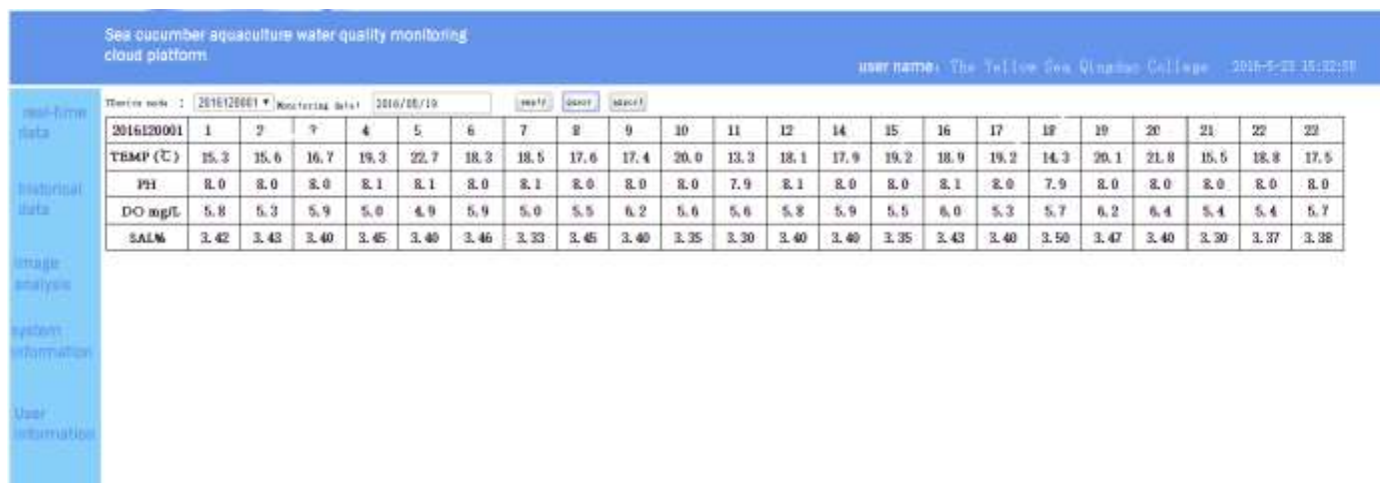

Fig.6 data query 


\section{Test}

Data query module test results are shown in Table 4.

Table 4 test results of data query module

\begin{tabular}{|c|c|c|c|}
\hline \multicolumn{4}{|c|}{ Test result number: $002-\mathrm{v} 1.0-001$} \\
\hline \multicolumn{4}{|c|}{ Use case number: 002} \\
\hline Test person & style & Test version & date of observation \\
\hline Heqianqian & query window & $\mathrm{v} 1.0$ & 2016-05-21 \\
\hline \multicolumn{4}{|c|}{ describe } \\
\hline step & \multicolumn{2}{|c|}{ test result } & Whether to match \\
\hline 1 & \multicolumn{2}{|c|}{ System tips: not select nodes, can not query } & yes \\
\hline 2 & \multicolumn{2}{|c|}{ Display information correctly } & yes \\
\hline 3 & \multicolumn{2}{|c|}{ System tips: no data information, can not be exported } & yes \\
\hline 4 & \multicolumn{2}{|c|}{ Data normal export } & yes \\
\hline Problem feedback & \multicolumn{3}{|c|}{ no } \\
\hline
\end{tabular}

\section{Conclusion}

The test results show that this system realized presupposition functional requirements, can realize the mariculture water information monitoring and early warning, data storage and query. The system has simple structure, high reliability, low cost, and can realize the data anytime, anywhere acquisition and control, with a very broad application value in the market.

The project number: J15LN59、J16LN78

\section{References}

[1] Ke Zhou Jun way. The real-time database system [J]. Computer Engineering greenhouse agricultural production monitoring configuration software, 2004 (12): 186-188.

[2] Ding Shengjian. Design and implementation of the ZigBee protocol and gateway system in the water quality monitoring system based on [D]. WSN Anhui University, 2013 (05).

[3]WEN-TSAIS,JUi-HOC,HSI-CHUNW.Remote fish aquaculture monitoring system based on wireless transmissin technology[C]//International Conference on Information Science.Sapporo:IEEE,2014:540-544.

[4] Yu Hongxia. Design and implementation of network examination system based on ASP.NET and [D]. XML Jiangxi: Jiangxi Normal University, 2008

[5] Peng FA. The development of the five parameter monitor for aquaculture water quality [D]. Shandong: Shandong Agricultural University, 2014 (06). 